Article

\title{
Power Spectral Analysis of Heart Rate Variability in Hypertensive Male
}

\author{
Rehnuma Tabassum ${ }^{1}$, Noorzahan Begum ${ }^{2}$, Sultana Ferdousi ${ }^{3}$, Shelina Begum ${ }^{4}$, Taskina Ali ${ }^{5}$
}

\begin{abstract}
Background: Essential hypertension is associated with altered cardiovascular autonomic nerve function. Heart Rate Variability (HRV) analysis is an important tool for quantitative measurement of autonomic nerve activity. Objective: To assess the cardiac autonomic nerve function status in essential hypertension by analyzing power spectral measures of heart rate variability. Methods: This cross sectional study was carried out in the Department of Physiology, Bangabandhu Sheikh Mujib Medical University between July 2008 and June 2009. Sixty male hypertensive patients with age range 40-60 years (group B) were enrolled from the Out Patient Department of Cardiology,BSMMU, Dhaka. Thirty age and sex matched apparently healthy normotensive subjects (group A) were studied as control, Hypertensive patients were further divided into group $\mathrm{B}_{1}$ consisting of 30 untreated patients on their 1 st day of diagnosis and group $B_{2}$ consisting of 30 patients under antihypertensive therapy. Power Spectral measures of Heart Rate Variability (HRV) such as total power, low frequency (LF) and high frequency power(HF) LH/HF ratio were assessed by a digital Polygraph. For statistical analysis , Independent sample t-test, One-way ANOVA test and Pearson's correlation coefficient test were done as applicable. Results: Mean TP,LF,HF and HF norm was significantly $(\mathrm{p}<0.001)$ lower and LF/HF ratio and LF norm were significantly $(\mathrm{p}<0.001)$ higher in both untreated and treated hypertensive patients compared to those of normotensive subjects. Again, significant differences of LF norm and HF norm and LF/HF ratio were found between the two hypertensive groups. The LF/HF ratio and LF norm were positively and HF norm was negatively correlated with SBP and DBP in both the hypertensive groups. However, all these findings were more marked in untreated hypertensive patients than those of treated group. Conclusion: Sympathovagal balance in hypertensive patients is towards higher sympathetic and lower vagal modulation and effective treatment of the patients can return the balance towards normal.
\end{abstract}

Key words: LF norm; HF norm; LF/HF ratio; hypertension

J Bangladesh Soc Physiol. 2011 June; 6(1): 32-38

For author affiliations, see end of text.

http://www.banglajol.info/index.php/JBSP

\section{Introduction}

$\mathbf{H}$

ypertension is an emerging health problem in Bangladesh among the cardiovascular diseases. The prevalence rate of hypertension is very high and more than $20 \%$ of the adults have hypertension. ${ }^{1}$ The adverse effects of hypertension principally involve the blood vessels, the retina, the heart, and the kidneys including the central nervous system. ${ }^{2-3}$

Evidence from studies of both animal and human suggested that autonomic nervous system plays a crucial role in the development of hypertension. ${ }^{4}$ The arterial baroreflex mechanism

J Bangladesh Soc Physiol. 2011 June; 6(1): 32-38 
regulates blood pressure through reflex effects on the heart, resistance vessels and renal excretion of sodium and water. ${ }^{5}$

There is evidence that faulty noradrenaline reuptake in the cardiac sympathetic nerves amplify the sympathetic neural signal in essential hypertensive patients. ${ }^{6}$

Essential hypertension is treated with drugs which themselves can modify the sympathoparasympathetic balance. ${ }^{7,8}$

The heart rate variability analysis is a powerful tool in assessment of the cardiac autonomic nerve function.. ${ }^{9}$ In frequency domain method, power spectral density analyzes the total power(TP) distributes as a function of frequency. Low frequency (LF) and high frequency (HF) are the components of total power in a spectrum of 2-5 minutes record. The autonomic modulations of HRV lead to variation in the distribution of the total power and the central frequency of LF and $\mathrm{HF}^{9}$

Evidences from various studies showed that HRV is lower in newly-onset untreated hypertensive and also in treated hypertensive patients compared to normotensive subjects. ${ }^{10,11}$

Various investigators from different countries reported lower LF power and HF power in untreated patients than those of healthy control. ${ }^{8,12-15}$ Some other group of researchers also observed similar findings in treated group when compared to normotensive control. ${ }^{13,15-17}$

Hypertension is one of the common cardiovascular problems in our country. Large number of cases remains unnoticed, which subsequently present with various complications. In addition to metabolic factors, many studies have documented sympathetic hyperactivity as the principal underlying cause for hypertension. Therefore, quantitative measurement of cardiac sympathetic nerve activity along with cardiovagal balance may throw some light on the role of autonomic modulation to develop hypertension and also change in the autonomic activity after treatment with antihypertensive therapy. Therefore, the present study was carried out to observe the autonomic nerve function status in both untreated and treated hypertensive patients by analysis of HRV specteral parameters.

\section{Methods}

This cross sectional study was carried out to observe the HRV by power spectral analysis in 60 male hypertensive patients with age ranged from 40-60 years (group B) in the Department of Physiology, Bangabandhu Sheikh Mujib Medical University between July 2008 and June 2009. Hypertensive patients were divided into $\mathrm{B}_{1}$ (30 untreated patients on their $1^{\text {st }}$ day of diagnosis) and $B_{2}$ (30 patients with antihypertensive medication). For comparison, 30 age, sex and BMI matched apparently healthy normotensive subjects (group A) were also studied. The hypertensive patients were selected from the Out Patient Department of Cardiology, BSMMU, Dhaka and the control group was selected by personal contact. Patients with history of heart diseases, secondary hypertension, diabetes mellitus, renal diseases and psychic disorders were excluded from the study.

After selection, the subject was thoroughly informed about the objectives and detail procedure of the study before examination. If they agreed to enroll for the study, informed written consent was taken from them. In order to prepare the subjects for test the subjects were advised to have their meal by 9:00 pm on the previous night, to remain free from any physical or mental stress, not to take sedatives or any drugs affecting central nervous system and to have a good sleep at night before the day of examination. The subjects were also requested to have a light breakfast without tea or coffee and then to attend the Autonomic Nerve Function Laboratory in the Department of Physiology of Bangabandhu Sheikh Mujib 
Medical University between 9:00 to11:00 a.m. on the day of test. Then the subject was interviewed and detail history regarding personal history, drug history, past medical history was taken. Then thorough physical examinations and anthropometric measurement including height and weight were taken and BMI was calculated from measured height and weight. All information were recorded in a prefixed questionnaire. Then he was kept under complete bed rest in supine position for 15-20 minutes in a cool and calm environment. During this period he was advised not to talk, eat or drink and also not to perform physical or any mental activity, even sleep. Then all preparations for recording of the Heart Rate Variability parameters were made by connecting the standard leads to the ECG channel of a digital Polyrite and a 5 minutes recording was taken in resting supine position.Heart Rate Variability parameters in frequency domain method like Total Power (TP),VLF power, LF power, HF power, LF norm, HF norm and LF/HF ratio were measured by Polygraph (RMS Polyrite D, version 2.2) and for statistical analysis Independent sample t-test, One-way ANOVA test and Pearson's correlation coefficient test were done as applicable.

\section{Results}

Subjects of all the groups were matched for age and BMI.(Table I).

The mean resting pulse rate $(\mathrm{p}<0.05)$, systolic (SBP) and diastolic (DBP) blood pressure $(p<0.001)$ were significantly higher in group $B_{1}$ than those of group $A$ and $B_{2}$. But statistically no significant differences were observed when these parameters were compared between group $A$ vs group $B_{2}$. Again, SBP and DBP were significantly higher $(\mathrm{p}<0.001)$ in group $\mathrm{B}_{1}$ compared to $\mathrm{B}_{2}$ but pulse rate was similar. (Table II)

The mean total power $(\mathrm{p}<0.001)$, LF power $(\mathrm{p}<0.01)$ and HF power $(\mathrm{p}<0.001)$ were significantly lower in both group $\mathrm{B}_{1}$ and $\mathrm{B}_{2}$ than that of group $A$, However, no significant difference was observed between group $B_{1}$ vs group $\mathrm{B}_{2}$.(Table III).
Table I: Age and BMI in different groups $(\mathrm{n}=90)$

\begin{tabular}{lcc}
\hline Groups & Age(years) & BMI $\left(\mathrm{kg} / \mathrm{m}^{2}\right)$ \\
\hline $\mathrm{A}(\mathrm{n}=30)$ & $48.37 \pm 8.03$ & $24.46 \pm 3.28$ \\
$\mathrm{~B}_{1}(\mathrm{n}=30)$ & $49.77 \pm 7.7$ & $25.37 \pm 2.93$ \\
$\mathrm{~B}_{2}(\mathrm{n}=30)$ & $48.13 \pm 6.24$ & $23.47 \pm 4.16$ \\
\hline
\end{tabular}

\section{Statistical analysis}

\begin{tabular}{llc}
\hline Groups & \multicolumn{2}{c}{ p values } \\
\hline A vs $B_{1}$ vs B $_{2}{ }^{a}$ & $0.651^{\text {ns }}$ & $0.115^{\text {ns }}$ \\
A vs $B_{1}{ }^{b}$ & $0.493^{\text {ns }}$ & $0.263^{\text {ns }}$ \\
A vs $B_{2}{ }^{b}$ & $0.900^{\text {ns }}$ & $0.308^{\text {ns }}$ \\
$\mathrm{B}_{1}$ vs $B_{2}{ }^{\text {b }}$ & $0.370^{\text {ns }}$ & $0.05^{\text {ns }}$ \\
\hline
\end{tabular}

Data were expressed as mean $\pm \mathrm{SD}$. Statistical analysis were done by One-way ANOVA ${ }^{\mathrm{a}}$ and Independent sample t-test ${ }^{b}$

Group A: Apparently healthy normotensive (control).

Group B. Hypertensive(study group)

$\mathrm{B}_{1}$-Untreated. $\mathrm{B}_{2}$ : Treated.

$\mathrm{BMI}=$ Body Mass Index, $\mathrm{ns}=\mathrm{p}>0.05, \mathrm{n}=$ number of subjects.

Table II: Resting Pulse Rate and BP in different groups ( $\mathrm{n}=90)$

\begin{tabular}{lccc}
\hline Groups & $\begin{array}{c}\text { Pulse } \\
(\mathrm{bpm})\end{array}$ & $\begin{array}{c}\text { SBP } \\
(\mathrm{mm} \text { of Hg) }\end{array}$ & $\begin{array}{c}\text { DBP } \\
(\mathrm{mm} \text { of Hg) }\end{array}$ \\
\hline $\mathrm{A}(\mathrm{n}=30)$ & $71.23 \pm 7.28$ & $112.67 \pm 10.73$ & $74.43 \pm 8.71$ \\
$\mathrm{~B}_{1}(\mathrm{n}=30)$ & $77.30 \pm 10.22$ & $156.33 \pm 16.18$ & $101.50 \pm 8.63$ \\
$\mathrm{~B}_{2}(\mathrm{n}=30)$ & $74.4 \pm 9.09$ & $117.83 \pm 14.24$ & $78.33 \pm 10.20$ \\
\hline
\end{tabular}

Statistical analysis

\begin{tabular}{|c|c|c|c|}
\hline \multicolumn{2}{|l|}{ Groups } & \multicolumn{2}{|l|}{$\mathrm{p}$ values } \\
\hline$A$ vs $B_{1}$ vs $B_{2}{ }^{a}$ & $0.036^{*}$ & $0.000 * * *$ & $0.000 * * *$ \\
\hline $\mathrm{A}$ vs $\mathrm{B}_{1}^{\mathrm{b}}$ & $0.010^{*}$ & $0.000 * * *$ & $0.000 * * *$ \\
\hline$A$ vs $B_{2}{ }^{b}$ & $0.142 \mathrm{~ns}$ & 0.118 ns & 0.117 ns \\
\hline $\mathrm{B}_{1}$ vs $\mathrm{B}_{2} \mathrm{~b}$ & $0.250 \mathrm{~ns}$ & $0.000 * * *$ & $0.000 * * *$ \\
\hline
\end{tabular}

Data were expressed as mean \pm SD. Statistical analysis were done by One-way ANOVA ${ }^{\mathrm{a}}$ and Independent sample t-test ${ }^{\mathrm{b}} \mathrm{SBP}=$ Systolic blood pressure, $\mathrm{DBP}=$ Diastolic blood pressure.

$* * *=\mathrm{p}<0.001, * *=\mathrm{p}<0.01, *=\mathrm{p}<0.05$, ns $=$ $\mathrm{p}>0.05$.

J Bangladesh Soc Physiol. 2011 June; 6(1): 32-38 
Power Spectral Analysis of Heart Rate Variability in Hypertensive Male

Article

Table III: Frequency domain measures of HRV in different groups ( $\mathrm{n}=90)$

\begin{tabular}{|c|c|c|c|}
\hline Groups & Total power(ms²) & LF power(ms²) & HF power(ms $\left.{ }^{2}\right)$ \\
\hline$A(n=30)$ & $2815.4 \pm 813.8$ & $435 \pm 347.6$ & $621 \pm 606.5$ \\
\hline$B_{1}(n=30)$ & $1487.4 \pm 291.2$ & $196.1 \pm 179.7$ & $49.7 \pm 44.4$ \\
\hline $\mathrm{B}_{2}(\mathrm{n}=30)$ & $1674.8 \pm 437.3$ & $185 \pm 171.6$ & $77.2 \pm 74.1$ \\
\hline \multicolumn{4}{|c|}{ Statistical analysis } \\
\hline Groups & & $\mathrm{p}$ values & \\
\hline$A$ vs $B_{1}$ vs $^{a}{ }^{a}$ & $0.000 * * *$ & $0.000 * * *$ & $0.000 * * *$ \\
\hline A vs $B_{1}{ }^{b}$ & $0.000 * * *$ & $0.001 * *$ & $0.000 * * *$ \\
\hline$A$ vs $B_{2}^{b}$ & $0.000 * * *$ & $0.001 * *$ & $0.000 * * *$ \\
\hline $\mathrm{B}_{1} \mathrm{vs} \mathrm{B}_{2}^{\mathrm{b}}$ & $0.056 \mathrm{~ns}$ & $0.808^{\mathrm{ns}}$ & $0.087^{\mathrm{ns}}$ \\
\hline
\end{tabular}

Data were expressed as mean \pm SD. Figures in parentheses indicate ranges.

Statistical analysis were done by One-way ANOVA ${ }^{\mathrm{a}}$ and Independent sample t-test ${ }^{\mathrm{b}}$

VLF=Very Low Frequency LF= Low Frequency HF= High Frequency

Table IV: Frequency domain measures of HRV in different groups (n=90)

\begin{tabular}{lccc}
\hline Groups & LF norm(nu) & HF norm(nu) & LF/HF \\
\hline $\mathrm{A}(\mathrm{n}=30)$ & $59.70 \pm 3.65$ & $38.91 \pm 4.70$ & $1.5 \pm 0.23$ \\
$\mathrm{~B}_{1}(\mathrm{n}=30)$ & $80.56 \pm 3.29$ & $19.44 \pm 3.29$ & $4.32 \pm 1.06$ \\
$\mathrm{~B}_{2}(\mathrm{n}=30)$ & $71.13 \pm 4.75$ & $28.87 \pm 4.75$ & $2.55 \pm 0.57$ \\
\hline Statistical analysis & & \\
\hline Groups & & p values & \\
\hline A vs B ${ }_{1}$ vs B $_{2}{ }^{\text {a }}$ & $0.000^{* * *}$ & $0.000^{* * *}$ & $0.000^{* * *}$ \\
A vs B ${ }_{1}{ }^{\mathrm{b}}$ & $0.000^{* * *}$ & $0.000^{* * *}$ & $0.000^{* * *}$ \\
$\mathrm{~A}$ vs B ${ }_{2}{ }^{\mathrm{b}}$ & $0.000^{* * *}$ & $0.000^{* * *}$ & $0.000^{* * *}$ \\
$\mathrm{~B}_{1}$ vs B $_{2}{ }^{\mathrm{b}}$ & $0.000^{* * *}$ & $0.000^{* * *}$ & $0.000^{* * *}$ \\
\hline
\end{tabular}

Data were expressed as mean \pm SD. Figures in parentheses indicate ranges.

Statistical analysis were done by One-way ANOVA ${ }^{\mathrm{a}}$ and Independent sample t-test ${ }^{\mathrm{b}}$

Group A: Apparently healthy normotensive (control).

Group B: Hypertensive(study group) $\quad B_{1}$-Untreated. $\quad B_{2}$ - Treated.

LF norm $=$ LF power in normalized unit [(LF/Total power-VLF) $\mathrm{x} 100]$,

HF norm =High frequency in normalized unit [(HF/Total power-VLF) x100],

$\mathrm{LF} / \mathrm{HF}=$ ratio of low and high frequency power. $* * *=\mathrm{p}<0.001 \mathrm{n}=$ number of subjects.

J Bangladesh Soc Physiol. 2011 June; 6(1): 32-38 
Again the LF norm and LF/HF ratio were significantly $(\mathrm{p}<0.001)$ higher and HF norm were significantly lower in both group $B_{1}$ and $B_{2}$ when compared to those of group $A$ and also in $B_{1}$ compared to that of $\mathrm{B}_{2}$. (Table IV).

\section{Discussion}

In the present study, values of HRV parameters in healthy control group were almost similar to those reported by the various investigators from different countries ${ }^{12,14,15,18}$ and also from our country ${ }^{19-21}$

In this study, the mean resting pulse rate and blood pressure was significantly higher in untreated hypertensive patients in comparison to those of healthy normotensive and treated hypertensive groups. But these values showed no statistically significant difference between healthy normotensive and treated hypertensive groups. Similar type of findings was also reported by the various investigators from different countries ${ }^{4,11,14,15,18}$.

The mean total power, and HF power in both untreated and treated hypertensive were significantly lower than those of healthy control. However, no significant difference was observed between two groups of hypertensive patients. Similar findings were also reported by different researchers of various countries $8,12-18,22$

The LF norm and LF/HF ratio were significantly higher and HF norm power was significantly lower both in both groups of hypertensive than those of healthy control. Again, untreateded hypertensive patients had significantly higher values of LF norm and LF/HF ratio and significantly lower HF norm than those of treated groups. Almost similar type of findings was also reported by of investigators of different countries. 4,8,12,14, 15,23,24.

Evidences from various investigators suggested that altered heart rate variability reflects the presence of autonomic nerve dysfunction and thereby may leads to arterial hypertension. ${ }^{10,14,18,2}$ Essential hypertension is commonly neurogenic and attributed to sympathetic overdrive and may be associated with parasympathetic inhibition. 5,25

It has also been suggested that increased rate of sympathetic nerve firing and also increase in density of sympathetic innervations might cause sympathetic over activity in hypertensive patients. Again, the cotransmission of adrenaline in cardiac sympathetic nerve along with impaired removal of noradrenaline from the synaptic cleft might also be the contributory factors for sympathetic over activity in essential hypertension ${ }^{6}$ This is supported by evidence of elevated plasma norepinephrine level in established essential hypertensive patients. ${ }^{26,27}$

Again, it has been suggested that â-adrenergicmediated vasodilation might have some contribution in sympathetic overdrive in essential hypertension. ${ }^{28,-10}$.

In the present study, sympathetic overactivity may be the cause of hypertension as evidenced by the higher values of LF norm and LF/HF. However, decreased values of total power, HF power and HF norm in hypertensive patients are suggestive of reduced vagal tone. All these changes indicate shifting of sympathovagal balance towards sympathetic predominance which is also in favour of sympathetic overactivity in essential hypertension.

\section{Conclusion}

The present study concludes that sympathovagal balance may be altered towards sympathetic predominance in essential hypertension which is supported by markedly decreased parasympathetic activity with slightly increased sympathetic modulation observed with hypertensive patients

\section{Author affiliations}

1. *Rehnuma Tabassum, Assistant professor, Department of Physiology, East West Medical College,Tongi,Gazipur.Email:rehnuma.15@gmail.com.

2. Noorzahan Begum, Professor, Department of Physiology,Bangabandhu Sheikh Mujib Medical University(BSMMU),Bangladesh.Email:noorzahan52@gmail.com.

3. Sultana Ferdousi, Associate professor, Department of Physiology, Bangabandhu Sheikh Mujib Medical University(BSMMU),Bangladesh.Email:sferdousiratna@gmail.com.

4. Shelina Begum, Professor, Chairman Department of Physiology, Bangabandhu Sheikh Mujib Medical Univers i t y ( B S M M U ), B angla d e s h . Email:shelina1982@gmail.com

5. Taskina Ali, Assistant Professor Department of Physiology, Bangabandhu Sheikh Mujib Medical University(BSMMU),Bangladesh.Email:taskinadr@gmail.com.

*For correspondence

J Bangladesh Soc Physiol. 2011 June; 6(1): 32-38 


\section{Article}

Power Spectral Analysis of Heart Rate Variability in Hypertensive Male

\section{References}

1. Shahriar I, Haque Z,Momen A. Patterns of Antihypertensive Drugs Used in Two Postgraduate Institutions. Journal of Dhaka National Medical college and Hospital.2008; 13(1):41-44.

2. Haslett C,Chilvers ER,Boon NA,Colledge NR,Hunter JAA.Davidson's Principles and Practice of Medicine.19 $9^{\text {th }}$ ed. Edinburgh:Elsivier science Limited;2002.388-391p.

3. Wu J, Lu F, Yang Y, Lin T, Chen J, Wu C, HuangY, Chang C. Epidemiological Study on the Effect of Pre-hypertension and Family History of Hypertension on Cardiac Autonomic Function. J Am Coll Cardiol.2008; 51:1896-901.

4. Julius S. Autonomic nervous system dysregulation in human hypertension. Am J Cardiol 1991; 67: 3B-7B.

5. Esler M, Rumantir M, Kaye D, Jennings G, Hastings J, Socratous F, Lambert G. Sympathetic Nerve Biology in Essential Hypertension.Clin Exp Pharmacol Physiol. 2001; 28(12):986-89.

6. Pagani M, Lucini D. Autonomic dysregulation in essential hypertension: Insight from HeartRrate and Arterial Pressure Variability. Auton Neurosci. 2001; 90: 76-82.

7. Guzzetti S, Piccaluga E, Casati R. Sympathetic predominance in essential hypertension: A study employing spectral analysis of heart rate variability. J Hypertens 1988; 6:711-717.

8. HeartRate Variability Testing.[Internet ] 2008 [cited May 2008] Available from:http:// www.docgeorge.com.

9. Singh JP, Larson MG, Tsuji H. Reduced heart rate variability in new-onset hypertension. Insights into pathogenesis of hypertension: The Framingham Heart study. Hypertension.1998; 32:293-297.

10. Srinivasa J, Bhat MR, Adhikari P. Comparative Study of Heart Rate Variability (HRV) during Deep Breathing in Normotensive and Hypertensive Subjects. JIACM. 2002; 3(3): 266-70.

11. Kaftan AH and Kaftan O.QT Intervals and Heart Rate Variability in Hypertensive Patients.Jpn Heart J.2000; 41(2):173-82.

12. Sevre K, Johan D, Lefrandt, Nordby G, Os I, Mulder M, Reinold OB, Gans, Rostrup M, Smit JA. Autonomic Function in Hypertensive and Normotensive Subjects:Importance of Gender. Hypertension. 2001; 37:1351-356.

J Bangladesh Soc Physiol. 2011 June; 6(1): 32-38
13. PavithranP, Madanmohan, Mithun R, Jomal M, Nandeesha H. Heart Rate Variability in MiddleAged Men with New-Onset Hypertension. Annals of Noninvasive Electrocardiol.2008; 13(3):24248 .

14. Mussalo H, Vanninen E, Ikäheimo R, Laakso M, Länsimies E, Hartikainen J. Heart rate variability and its determinants in patients with severe or mild essential hypertension.Clin Physiol. 2008; 21(5):594-604.

15. Huikuri HV, Ylitalo A, Pikkujamasa SM, et al. Heart rate variability in systemic hypertension. Am J Cardiol. 1996; 77:1073-1077.

16. Dietrich FD, Schindler C, Schwartz J, Barthelemy J, Tschopp J, Roche $\mathrm{F}$, Eckardstein A, Brandli O, Leuenberger P, Gold DR, Gaspoz J, Ackermann-Liebrich U and SAPALDIA Team. Heart Rate Variability In Aging Population and Its Association With lifestyle and Cardiovascular Risk Factors : results of the SAPALDIA study. Europace.2006; 8:521-29.

17. Prakash ES, Madanmohan, Sethuraman KR. Cardiovascular autonomic regulation in subjects with normal blood pressure, high-normal blood pressure and recent-onset hypertension. Clin Exp Pharmacol Physiol. 2005; 32:488-94.

18. Kabir MR. Study on heart rate variability in patients with hyperthyroidism. [Thesis] [Dhaka (Bangladesh)]: BSMMU.2008.

19. Ahmed M. Assessment of Cardiac Autonomic Nerve Function Status by Heart Rate Variability in Hypothyroid Patients. [Thesis] [Dhaka (Bangladesh)]: BSMMU. 2009 July.

20. Mithun S. Comparative study of Cardiac Autonomic Nerve Function Status by Heart Rate Variability between sedentary and heavy workers. [Thesis] [Dhaka (Bangladesh)]: BSMMU. 2009 July.

21. Harrington,Frances, Murray, Alan, Ford, Gray. Relationship of baroreflax sensitivity and blood pressure in an older population.J Hypertens.2000; 18(11):1629-33.

22. Pikkujamsa SM, Huikuri HV, Airaksinen KE, Rantala AO, Kauma H, Lilja M, Savolainen MJ, Kesaniemi YA. Heart Rate Variability and Baroreflex Sensitivity In Hypertensive Subjects With and Without Metabolic Features of Insulin Resistance Syndrome. Am J Hypertens. 1998; 11:523-31. 
23. Nordby G, Os I, Kjeldsen SE, Eide I. Mild essential hypertension in nonobese premenopausal women is characterized by low renin. Am J Hypertens. 1992; 5:579-84.

24. Lucini D, Mela GS, Malliani A, et al. Impairment In Cardiac Autonomic Regulation Preceding Arterial Hypertension In Humans: Insights From Spectral Analysis of Beat-by-Beat CardioVascular Variability. Circulation. 2002; 106:2673-79.

25. Goldstein DS. The fact of organization. In: Goldstein DS, ed. Stress, Catecholamines, and Cardiovascular Disease. New York,NY: Oxford University Press; 1995:56-102.

26. Supiano M A, Hogikyan RV, Sidani MA, Galecki AT, Krueger JL. Sympathetic nervous system activity and á-adrenergic responsiveness in older hypertensive humans. Am J Physiol Endocrinol Metab. 1999; 276: E519-E528.

27. Feldman RD. Defective venous beta-adrenergic response in borderline hypertensive subjects is corrected by a low sodium diet. J Clin Invest.1990; 85: 647-652.

28. Naslund T, Silberstein DJ, Merrell WJ, Nadeau JH and Wood A JJ. Low Sodium Intake Corrects Abnormality In -Receptor-Mediated Arterial Vasodilation In Patients With Hypertension: Correlation With -Receptor Function In Vitro. Clin Pharmacol Ther. 1990; 48: 87-95.

29. Stein CM, Nelson R, Deegan R, He H,Wood M, Wood AJJ. Forearm Beta Adrenergic ReceptorMediated Vasodilation Is Impaired Without Alteration Of Forearm Norepinephrine Spillover In Borderline Hypertension. J Clin Invest.1995; 96: 579-85. 